целью и хотят познать мир. Именно он позволяет укрепить здоровье, возможность путешествовать.

$$
* * *
$$

1. Биржаков М.Б. Введение в туризм: Учебник. - Издание 8-е, переработанное и дополненное. - СПб.: "Издательский дом Герда", 20016. - 512 с.

2. Восколович, Н. А. Экономика платных услуг [Текст]/ Н. А. Восколович. - М.: Юнити-Дана, 2015. $399 \mathrm{c}$.

3. Виноградова М.В., Панина З.И. Организация и планирование деятельности предприятий сферы сервиса: Учебное пособие. - 2-е изд. - М.: издательско-торговая корпорация "Дашков и Ко", 2006. $464 \mathrm{c}$.

4. Джапарова, Р. Маркетинг услуг профессионального образования // Маркетинг. - 20012. - № 4. - С. $55-65$.

5. Дурович А. и Копаев А. Теория и методика игры: учебник и практикум для СПО. - М.: Издательство Юрайт, 2016. - 370 с.

6. Ермаченкова О. А. Маркетинговые исследования в туризме // Молодой ученый. — 2014. — №4. C. 513-515.

7. Зорин, И. В., Квартальнов В. А.Туризм как вид деятельности: Учебник. - М.: Высшая школа, 2013-234 c.

8. Квартальнов В.А. Туризм: теория и практика. М., Финансы и статистика: 1998. - 279 с.

9. Кулибанова В.В. Маркетинг: сервисная деятельность. - СПб.: Питер, 2012. - 320 с.

10. Официальный сайт Консультант плюс [Электронный ресурc] -http://www.consultant.ru

11. Синяева, И.М. Маркетинг услуг: Учебник / И.М. Синяева, О.Н. Романенкова. - М.: Дашков и К, 2015. - $252 \mathrm{c}$.

\title{
Качанов М.Д. \\ «Работа без границ»: развитие цифрового рынка труда в ЕАЭС в контексте отношения к мигрантам в России
}

Сибирский федеральный университет

(Россия, Красноярск)

doi: $10.18411 / 1 j-07-2021-54$

\section{Аннотация}

В статье рассматривается проблема запуска цифрового проекта стран-членов ЕАЭС «Работа без границ» на фоне ухудшения отношения к мигрантам в России со стороны принимающего населения. Автор представляет результаты анализа восприятия россиянами миграционной ситуации в России, в частности, по отношению к государствам членам ЕАЭС. Уделяется особое внимание проблемам восприятия россиянами различных мигрантских контингентов, принятия населением трудовых мигрантов, а также изменения общественных настроений по отношению к мигрантам в условиях пандемии в России в 2020 г.

Ключевые слова: Россия, мигранты, ЕАЭС, цифровой проект, межэтнические отношения, пандемия.

\section{Abstract}

The article discusses the problem of starting the digital project of the EAEU member states «Work without Borders» against the background of the deteriorating attitude of the host population towards migrants in Russia. The author presents the results of an analysis of Russians' perceptions of the migration situation in Russia, particularly in relation to EAEU member states. It focuses in particular on how Russians perceive different migrant populations, the acceptance of labour migrants by the population and changes in public attitudes towards migrants in the context of the pandemic in Russia in 2020.

Keywords: Russia, migrants, EAEU, digital project, interethnic relations, pandemic. 
Правительства по всему миру все чаще воспринимают иммиграцию как беспроигрышный фактор в их адаптации к конкурентным и основанным на знаниях условиям глобальной экономики, способствующий экономическому росту, и как средство решения проблем стареющих обществ. Миграция выполняет множество важных функций, таких как компенсация потерь населения, восполнение нехватки рабочей силы, устранение диспропорций на рынке труда и активизация социальных и культурных обменов. В то же время она обеспечивает решение проблем национальной и международной безопасности и выявляет некоторые угрозы и риски - рост безработицы, рост преступности, растущая угроза терроризма, искажение ценностей коренных народов, распространение болезней и т. д.

По данным недавнего доклада Экономического и социального совета $\mathrm{OOH}$ (ЭКОСОС), Россия в 2020 году оказалась на четвертом месте среди стран с самым высоким числом мигрантов. Миграционная политика является ответом на резкую тенденцию депопуляции в России в постсоветский период. Однако за это средство приходится платить все большую плату в виде нелегальной миграции и миграции низкоквалифицированной рабочей силы.

В данной статье речь пойдет о цифровом проекте «Работа без границ». Что же представляет собой проект? Это поисковая система, позволяющая каждому гражданину или работодателю искать вакансии или резюме, которые содержатся в национальных информационных системах государств - членов Евразийского экономического союза. В РФ это портал «Работа в России», информационными партнерами которого являются и аналогичные крупные коммерческие ресурсы, например, «Яндекс.Работа».

Создаваемая поисковая система позволит получить доступ к информации о вакантных рабочих местах и соответствующих кандидатах, которая содержится в информационных системах государств-членов по вопросам трудоустройства и занятости. В результате пользователям системы, то есть кандидатам и работодателям, будет предоставлена возможность выбрать одну или несколько стран Союза, в которых они должны искать работу или отбирать персонал, для формирования уникального поискового запроса к национальным информационным системам, получить доступ к информации о вакансиях и резюме, а также возможность взаимодействия в режиме реального времени. Таким образом, проект поможет сформировать общий рынок труда, ускорить процессы свободного движения рабочей силы и обеспечить мобильность трудовых ресурсов.

Вопросы миграции и миграционной политики играют заметную роль в отечественном дискурсе на протяжении последних десятилетий. Так, в представлении среднестатистического россиянина сложился прочный стереотип образа типичного трудового иммигранта из СНГ - представителя нерусской национальности с низкой зарплатой, как правило, разнорабочего (дворника, грузчика, таксиста, строителя или продавца на рынке). Вопреки тому, что трудовые мигранты для государства представляют собой не только дешевую рабочую силу и возможность решения проблемы нехватки рабочей силы, многие российские граждане воспринимают иммигрантов в целом негативно.

Согласно отчету Евразийского банка развития (ЕАБР), «Интеграционный барометр», отмечается ухудшение ситуации, связанной с готовностью россиян принимать трудовых мигрантов в своей стране. В среднем 77\% жителей стран ЕАЭС разделяют принципы свободы передвижения, трудоустройства, проживания и обучения в рамках Союза. В то же время в России наблюдается неизменно высокий процент неприятия приезжих трудовых мигрантов - такую позицию высказали 53\% населения (в 2012 году - 46\%). Так, большинство россиян ответили, что среди стран СНГ нет таких, чьих мигрантов они хотели бы видеть в РФ (25\%), либо ушли от ответа (27\%) (рис. 1). 


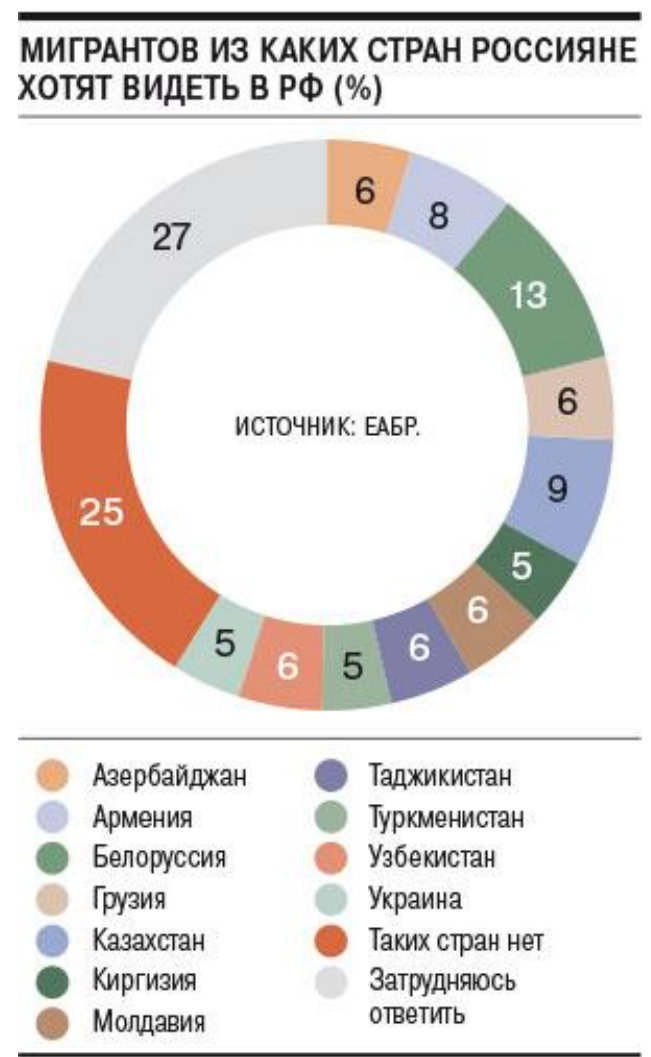

Рисунок 1. Отношение россиян кмигрантам из разных стран

Кроме того, подобную динамику отмечает и замруководителя администрации президента России Магомедсалам Магомедов. По его словам, в 2020 году почти каждый четвертый из опрошенных выразил свое негативное отношение к мигрантам. Одновременно с этим наблюдается негативная тенденция. Отношение к мигрантам только ухудшается: число людей, отрицательно настроенных по отношению к мигрантам, увеличилось на 7,5 \%. Подобное положение дел значительно воздействует на качество межэтнических отношений.

Вдобавок к этому большинство россиян поддерживают идею привлечения заключенных на работу в тех сферах, где трудятся мигранты. Согласно опросу Всероссийского центра изучения общественного мнения (ВЦИОМ), 71\% респондентов выразили свое согласие (Таблица 1).

Таблииа 1.

Распределение ответов на вопрос: «Как Вы относитесь к предложению привлекать осужденных на работу в тех сферах, где обычно работают трудовые мигранты, например, на крупных стройках или промышленных объектах?», \% опрошенных

\begin{tabular}{|c|c|c|c|c|c|c|}
\hline & $\begin{array}{c}\text { Все } \\
\text { опрошен } \\
\text { ные }\end{array}$ & $\begin{array}{c}18-24 \\
\text { года }\end{array}$ & $\begin{array}{c}25-34 \\
\text { года }\end{array}$ & $\begin{array}{c}35-44 \\
\text { года }\end{array}$ & $\begin{array}{c}45-59 \\
\text { лет }\end{array}$ & $\begin{array}{c}60 \text { лет и } \\
\text { старше }\end{array}$ \\
\hline Полностью поддерживаю & 33 & 18 & 25 & 32 & 39 & 39 \\
\hline Скорее поддерживаю & 38 & 51 & 39 & 35 & 37 & 37 \\
\hline Скорее не поддерживаю & 11 & 21 & 16 & 11 & 8 & 8 \\
\hline Полностью не поддерживаю & 10 & 9 & 10 & 14 & 8 & 8 \\
\hline Затрудняюсь ответить & 8 & 1 & 10 & 8 & 8 & 8 \\
\hline
\end{tabular}

Таким образом, на сегодняшний день складывается ситуация, когда граждане России предпочитают видеть заключенных вместо трудовых мигрантов, считая первых более безопасными для общества. 
Интересную статистику об отношении к мигрантам приводит нам АНО “ЛевадаЦентр" (внесена в реестр некоммерческих организаций, выполняющих функции иностранного агента). Проведенный 20 - 26 августа 2020 года опрос показал, что большинство Россиян придерживаются идеи ограничения притока трудовых мигрантов (73\%) (Таблица 2). Стоит отметить, что данный показатель растет уже на протяжении четырех лет.

Таблища 2.

Распределение ответов на вопрос: «Как вы думаете, какой политики должно придерживаться правительство России относительно трудовых мигрантов:

ограничивать приток граждан из других государств, приезжающих в Россию на заработки - или, напротив, способствовать их притоку в Россию?», \% опрошенных

\begin{tabular}{|l|c|c|c|c|}
\hline & Июль 2017 & Июль 2018 & Август 2019 & Август 2020 \\
\hline $\begin{array}{l}\text { Ограничивать приток трудовых } \\
\text { мигрантов }\end{array}$ & 58 & 67 & 72 & 73 \\
\hline $\begin{array}{l}\text { Способствовать притоку трудовых } \\
\text { мигрантов }\end{array}$ & 6 & 14 & 9 & 11 \\
\hline Мне все равно & 30 & 17 & 15 & 14 \\
\hline Затруднились ответить & 6 & 2 & 4 & 3 \\
\hline
\end{tabular}

В большей степени отрицательно относятся к мигрантам те, кто наиболее негативно оценивает обстановку в месте своего проживания и особенно в своем субъекте Федерации, а также сложившуюся ситуацию в стране. Они гораздо сильнее, чем другие респонденты, обеспокоены всеми актуальными для страны проблемами. В частности, их особенно волнует социально-экономическая ситуация, что в основном связано с их неблагоприятным материальным положением. Так, доктор социологических наук В.И. Мукомель отмечает, что «если среди тех, кто оценивает свое материальное положение как очень хорошее или хорошее, с той или иной степенью неприязни к трудовым мигрантам относятся $14,5 \%$ респондентов, а среди оценивающих материальное положение как среднее - $18,7 \%$, то среди считающих свое материальное положение плохим или очень плохим - 30,7\% опрошенных».

Материальное положение является одним из наиболее весомых обстоятельств для возникновения негативного отношения к мигрантам, но не единственным. Пожалуй, их восприятие самих себя в социуме не менее важно: согласно опросам, ксенофобские и антимигрантские взгляды чаще озвучивают люди, которые тяжело переживают свое положение в социальной среде, неудовлетворенные практически всем - работой, доходами, положением в обществе и т.д. Так, по словам, В.И. Мукомеля «Если среди удовлетворенных жизнью респондентов лишь $15,9 \%$ выказывают неприязнь к мигрантам, то среди не удовлетворенных своей жизнью таковых вдвое больше $-32,7 \%$ ».

Уже не первый год прослеживается определенная ситуация: российские граждане в наибольшей степени испытывают негативное отношение к представителям Северного Кавказа, Закавказья, Средней Азии и Юго-Восточной Азии. При этом в последние годы отрицательное отношение к представителям Закавказья стало постепенно сменяться неприятием выходцев из Средней Азии. По данным опроса ВЦИОМ на конец 2018 года, отвечая на вопрос «Въезд в Россию представителей каких стран является нежелательным?», первые два места занимают представители Таджикистана (15\%) и Узбекистана (14\%), третье - Украины (13\%); на шестом месте Азербайджан (6\%); на восьмом - грузины (6\%); на девятом - уроженцы Кыргызстана (6\%), на двенадцатом - граждане Армении (4\%). Таким образом, мы видим ситуацию, где из пяти стран ЕАЭС, наблюдателя и возможного в будущем члена ЕАЭС Узбекистана, граждане двух государств, а именно Киргизии и Узбекистана, крайне отрицательно воспринимаются в российском обществе. 
Кроме того, согласно исследованиям, описанным в монографии «Социальные факторы межэтнической напряженности в России» 2017 года, приводится статистика людей, готовых работать под непосредственным руководством гражданина другого государства. Результаты опроса показали, что значительное число опрошенных не готово работать под началом руководителя другой национальности (Таблица 3).

Таблица 3.

Отрииательное отношение к работе под непосредственным руководством представителей разных этнических групп, \% от опрошенных

\begin{tabular}{|l|c|}
\hline \multicolumn{1}{|c|}{ Национальность } & \% отрицательно настроенных \\
\hline Армян & 33,2 \\
\hline Киргизов & 37,3 \\
\hline Узбеков & 39,6 \\
\hline Белорусов & 14,3 \\
\hline
\end{tabular}

Это видится мне важным, поскольку цель проекта «Работа без границ», по словам заместителя Министра экономического развития России Дмитрия Вольвача, заключается в привлечении квалифицированных кадров в перспективные секторы экономики, увеличении мобильности экономически активного населения ЕАЭС, сбалансированности рынка труда, ликвидации барьеров для ведения бизнеса и улучшения качества жизни людей на пространстве ЕАЭС. В то же время неготовность россиян работать совместно с гражданами стран-членов ЕАЭС ставит под вопрос возможную реализацию цели проекта «Работа без границ».

Свою роль в увеличении антимигрантских настроений сыграла и пандемия COVID-19. Количество трудовых мигрантов и членов их семей составляет примерно 89 миллионов человек. Примерно 95\% от этого числа мигрантов неспособны выехать из России во время пандемии, а в то же время примерно 2 миллиона потенциальных иностранных рабочих не могут пересечь границу России. Исключение составили граждане Беларуси, Украины и Молдовы, которые смогли покинуть страну через российско-украинскую и российско-белорусскую границы сухопутным способом. Основной контингент иностранных граждан теперь составляют представители государств Центральной Азии, в отношении которых чаще всего проявляются ксенофобские высказывания.

Вторая проблема заключается в вероятном въезде в Россию новых трудовых мигрантов, оставшихся без работы в своей стране. Маловероятно, что российские граждане примут трудовых мигрантов с радостью, поскольку в посткоронавирусный период многие россияне будут остро нуждаться в работе, в том числе низкооплачиваемой.

В этих условиях появляются новые угрозы в области обеспечения безопасности. Безработные мигранты являются благоприятной почвой для распространения экстремистских взглядов, где вербовщики террористических организаций имеют возможность осуществлять свою деятельность. В общинах мигрантов отмечается рост преступности. Прибывшие мигранты воруют как деньги, так и продукты питания, совершают нападения на дачи, частные владения и банкоматы. В январе-марте 2020 года официальная статистика МВД показала рост числа преступлений, совершенных иностранцами, на 2,5\%, примерно до 9,5 тысяч. При этом количество преступлений против иностранцев и лиц без гражданства, наоборот, выросло почти на 6\% по сравнению с аналогичным периодом прошлого года.

Учитывая такое положение дел, можно ли утверждать, что такое отношение россиян приведет к каким-либо открытым конфронтациям с мигрантами? И возможно ли с уверенностью сказать, к чему такая ситуация в итоге приведет? Точно ответить на оба вопроса невозможно. Однако такое отношение, безусловно, не способствует 
формированию благоприятной и безопасной среды в России. Следует опасаться, что чем неустойчивее экономическая ситуация в стране, чем ниже уровень заработной платы, тем больше граждане РФ будут воспринимать мигрантов как угрозу, как конкурентов в борьбе за рабочие места. Поэтому странам-членам ЕАЭС на сегодняшний день крайне важно учитывать такой фактор, как отношение самих граждан союза к различным миграционным проектам, формирующим общий рынок труда. Поскольку новая миграционная волна способна посеять хаос в российском обществе, увеличив тем самым количество радикальных националистов, на фоне экономического кризиса, вызванного пандемией COVID-19.

Чтобы уменьшить уровень напряженности в обществе, необходимо обеспечить выполнение таких задач, как удовлетворение основных потребностей, предоставление гарантий социальной защищенности, достижение высокого уровня жизни и т.д. Но также снизить межэтническую конфронтацию способен положительный экономический эффект миграции, отраженный в Миграционной стратегии России до 2035 года, который необходимо активно продвигать в СМИ, поскольку политика интеграции и адаптации мигрантов в российском обществе должна базироваться на прочной и продуманной информационной основе.

$$
* * *
$$

1. Григорьева К. С. [и др.]. Социальные факторы межэтнической напряженности в России: монография / [М. Ф. Черныш и др.] ; отв. ред. Ю. Б. Епихина, М. Ф. Черныш. — Москва : ФНИСЦ PAH, 2017. - $336 \mathrm{c}$.

2. Мукомель В. И. Миграционная ситуация и мигранты в восприятии россиян / В. И. Мукомель // Вестник Российской Нации. — 2021. - № 1-2 (77-78). — С. 53-68.

3. Иммиграция в Россию: благо или вред? [Электронный ресурс] // ВЦИОМ. - Режим доступа: https://wciom.ru/analytical-reviews/analiticheskii-obzor/immigracziya-v-rossiyu-blago-ili-vred (дата обращения: 28.06.2021).

4. Привлекательность РФ для трудовых мигрантов снижается [Электронный ресурс] // Коммерсантъ. - Режим доступа: https://www.kommersant.ru/doc/3975557 (дата обращения: 28.06.2021).

5. Наталья Мастикова об отношении россиян к мигрантам - Реальное время [Электронный ресурс] // Реальное время. - Режим доступа: https://realnoevremya.ru/articles/166801-natalya-mastikova-obotnoshenii-rossiyan-k-migrantam (дата обращения: 28.06.2021).

6. «В пабликах всплеск, что надо выгнать всех мигрантов из России» [Электронный ресурс] // БИЗНЕС Online. - Режим доступа: https://www.business-gazeta.ru/article/468732 (дата обращения: 28.06.2021).

7. Ксенофобия и национализм [Электронный ресурс] // Левада-Центр. - Режим доступа: https://www.levada.ru/2020/09/23/ksenofobiya-i-natsionalizm-2/ (дата обращения: 28.06.2021).

8. Жители России не готовы заместить иностранных мигрантов [Электронный ресурс] // Ведомости. - Режим доступа: https://www.vedomosti.ru/society/articles/2020/11/29/848719-zamestitgastarbaiterov (дата обращения: 28.06.2021).

9. ООН: Россия вошла в пятерку стран с самым высоким числом мигрантов в мире [Электронный pecypc] // Коммерсантъ. - Режим доступа: https://www.kommersant.ru/doc/4651795 (дата обращения: 28.06.2021).

10. Число россиян, негативно относящихся к мигрантам, выросло на 7,5 процента [Электронный pecypc] // РИА Новости. — Режим доступа: https://ria.ru/20210408/migranty-1727310702.html (дата обращения: 28.06.2021).

11. Совместный цифровой проект стран ЕАЭС «Работа без границ» стартует 1 июля [Электронный pecypc] // Минэкономразвития России. - Режим доступа: https://economy.gov.ru/material/news/sovmestnyy_cifrovoy_proekt_stran_eaes_rabota_bez_granic_startu et_1_iyulya.html (дата обращения: 28.06.2021).

12. Вместо тюрьмы - на работу? [Электронный ресурс] // ВЦИОМ. Новости. - Режим доступа: https://wciom.ru/analytical-reviews/analiticheskii-obzor/vmesto-tjurmy-na-rabotu (дата обращения: 28.06.2021).

13. International Migration 2020 [Electronic resource] // United Nation. -URL: https://www.un.org/development/desa/pd/news/international-migration-2020 (дата обращения: 28.06.2021). 